\title{
Venus Aerobot Multisonde Mission
}

\author{
By: James A. Cutts ${ }^{(1)}$, Viktor Kerzhanovich (1) J. (Bob) Balaram (1), Bruce Campbell (2), \\ Robert Gershman (1), Ronald Greeley (3), Jeffery L. Hall (1), Jonathan Cameron (1), \\ Kenneth Klaasen (1) and David M. Hansen (1)
}

\begin{abstract}
Robotic exploration of Venus presents many challenges because of the thick atmosphere and the high surface temperatures. The Venus Aerobot Multisonde mission concept addresses these challenges by using a robotic balloon or aerobot to deploy a number of short lifetime probes or sondes to acquire images of the surface. A Venus aerobot is not only a good platform for precision deployment of sondes but is very effective at recovering high rate data. This paper describes the Venus Aerobot Multisonde concept and discusses a proposal to NASA's Discovery program using the concept for a Venus Exploration of Volcanoes and Atmosphere (VEVA). The status of the balloon deployment and inflation, balloon envelope, communications, thermal control and sonde deployment technologies are also reviewed.
\end{abstract}

\section{INTRODUCTION}

Despite a number of successful missions to observe the surface and interior of Venus, a number of fundamental questions about the planet have yet to be resolved. The Venus Geoscience Aerobot (VGA), identified in NASA's Roadmap for Solar System Exploration (Fig 1 (a) and Ref 1), would make multiple excursions from high altitude in the Venus atmosphere to conduct observations at or near the surface in order to address these questions. The VGA mission requires a number of new technologies (Ref 2) including high temperature balloon materials, gondola thermal control systems and reversible fluid altitude control that will require a significant investment and at least five years of development. The VGA also

\section{Affiliations:}

(1) Jet Propulsion Laboratory, California Institute of Technology, Pasadena Califomia

(2) NASA Headquarters, Washington, D.C.

(3) Department of Geology, Arizona State requires an orbital relay system that significantly increases the overall mission cost. The Venus Aerobot Multisonde (VAMuS) Mission concept (Fig 1 (b) provides many of the scientific capabilities of the VGA, with existing technology and without requiring an orbital relay. It uses autonomous floating stations (aerobots) to deploy multiple dropsondes capable of operating for less than an hour in the hot lower atmosphere of Venus. The dropsondes, hereafter described simply as sondes, acquire high resolution observations of the Venus surface including imaging from a sufficiently close range that atmospheric obscuration is not a major concem and communicate these data to the floating stations from where they are relayed to Earth. In this paper, we describe the VAMuS mission concept and discuss a proposal to NASA's Discovery program to apply this concept for the Venus Exploration of Volcanoes and Atmospheres (VEVA) mission. A primary goal of the paper is to describe the progress in validating the key technologies needed for the mission.

\section{VENUS AEROBOT MULTISONDE MISSION CONCEPT}

The environment of Venus present major challenges for scientific exploration. A thick atmosphere of carbon dioxide, with a surface pressure of 90 bars and clouds and haze in the upper reaches totally obscures the planet's surface from remote observation from orbit except using radar imagery. The surface temperature is about $460^{\circ} \mathrm{C}$ and therefore long duration surface vehicles for in situ investigation require radioisotope powered refrigerators or high temperature electronics or both and become complex and extremely costly. Short duration observations in the lower atmosphere using small expendable sondes that survive for a few hours are a more practical solution. However, to be effective as an exploration tool, these sonde 


\section{Concepts for Venus Surface Exploration}

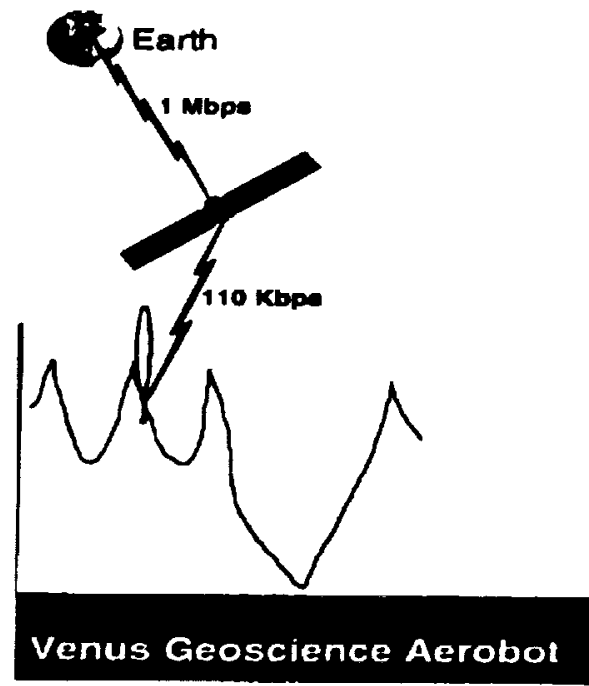

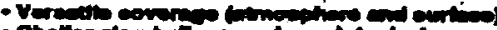

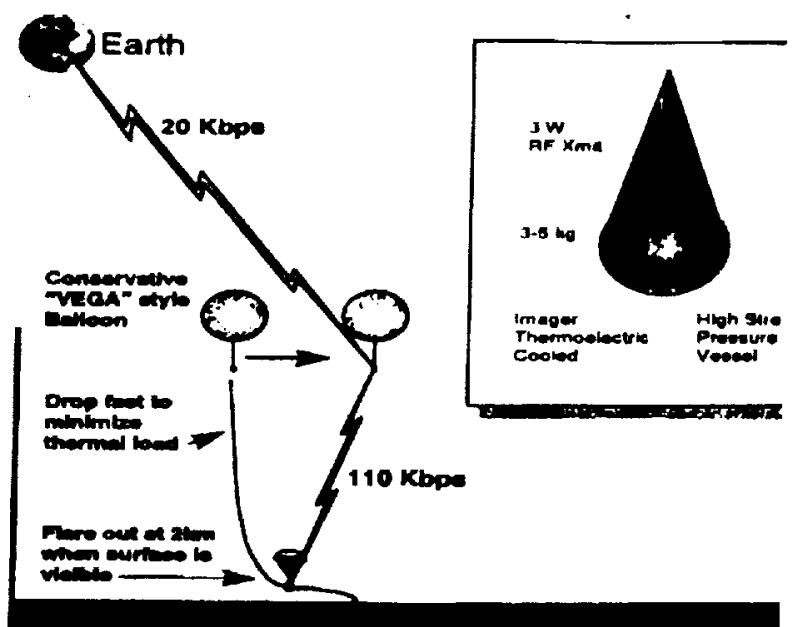

Venus Aerobot Multisonde

Fig 1 Comparison of Venus Geoscience Aerobot and Venus Aerobot Multisonde

must be able to communicate large amounts of data during their limited lifetime. In particular, the acquisition of high-resolution aerial imaging from near the surface of the planet for a number of targets of high scientific interest is of high priority.

The innovative feature of the VAMuS mission concept is to use aerobots (balloons) as both a delivery system and a high data rate communications relay for multiple low cost sondes. By using an aerobot for sonde delivery and data relay it is possible to deliver more sondes with higher accuracy and acquiring more data than when sondes are delivered to Venus by direct entry. Capture at Venus takes place by low-tech aeroentry eliminating the need for a costly propulsion or aerocapture stage. There is no requirement for the use of a relay spacecraft or orbiter at Venus.

Each aerobot upon emplacement consists of gondola and sondes suspended from a superpressure balloon. The balloon maintains the vehicle on a surface of constant atmospheric density in the Venus atmosphere except for perturbations caused by downdrafts and probe deployments. Superpressure balloon deployment and inflation was successfully demonstrated in 1985 in the Venera Vega balloon mission. Each of two Venera Vega balloons was tracked for two days in the Venus atmosphere.
Sonde Deployment: Aerobot deployment makes it possible to sequence deployments and target sondes based on what has already been learned from earlier missions. A radar map of Venus was obtained by the U.S. Magellan mission in the 1980s and allows important scientific target to be identified. From a float altitude of about $60-\mathrm{km}$, the sondes can be dropped with an accuracy of a few $\mathrm{km}$, which is much better than could be achieved from a direct entry.

After deployment from the aerobot, each sonde will descend rapidly towards the surface. At an altitude of about $3-\mathrm{km}$, the descent is arrested by a parachute or gliding device that permits an extended data acquisition near the Venus surface. Carried by the fast counter- rotating high altitude winds the aerobot will be carried rapidly to the west of the probe. The descent speed of the sonde, the thermal survival time and the period for which the floating station remains within range of the sonde are roughly commensurate, permitting about 15-30 minutes of high rate imaging data near the surface.

Communications Since the distance from the sondes to the aerobot is measured in tens of kms, high data rate communications (from 100kbps to $2 \mathrm{Mb} / \mathrm{sec}$ ) is possible with compact low power UHF $(400 \mathrm{MHz})$ transmitters and omnidirectional antennas on the probes and an omnidirectional 
receiving antenna on the aerobot. These data are stored on the aerobot for later transmission to Earth. Since the Venus-Earth distance is measured in tens of millions of kilometers, the free space communications loss is a factor of $10^{12}$ higher. However, the characteristics of the aerobot platform makes it possible to bridge this gap and return the data recovered by the probes in their short life time. Higher power transmitters can be deployed on the aerobot than on the probe and the relative stability of the platform and the benign thermal environment permits the use of a directional antenna for communication with Earth. The large directional antennas of the Deep Space Network are used to pick up the signal. A data rate of 10 to $20 \mathrm{~kb} / \mathrm{sec}$ appears feasible permitting return to Earth of all the data from the probes in a few tens of hours well within the
Volcanoes and Atmospheres (VEVA) mission was proposed to the Discovery program in June 1998 by a team led by Professor Ronald Greeley of Arizona State University (4). The VEVA team included participants from JPL, Lockheed Martin Corporation, Goddard Space Flight Center and several universities. The VEVA proposal incorporated many of the features of the VAMuS mission concept.

VEVA Science Theme: The goal of VEVA is to characterize the surface and lower atmosphere of Venus to determine if the planet has suffered a periodic global catastrophic resurfacing. The specific objectives of VEVA involve acquiring the first-ever-aerial photography of the surface of Venus and definitive in situ determination of the composition of Venus in its lower scale height.

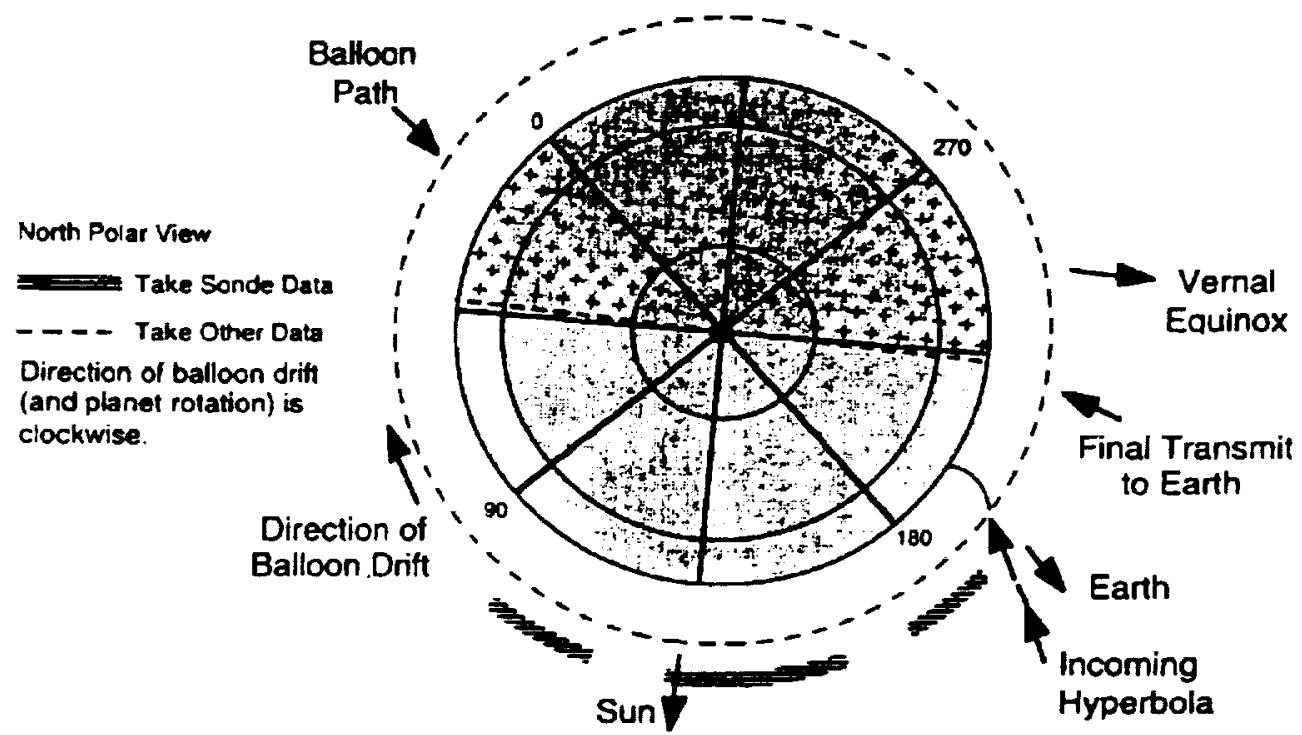

Fig 2: The geometry of Venus at the time of the VEVA mission. Atmospheric winds carry the balloon Gondolas around the planet in 7 days serving as a science platform and radio relay for the drop sondes

design lifetime of a Venus superpressure balloon.

\section{VENUS EXPLORATION OF VOLCANOES AND ATMOSPHERE (VEVA) MISSION}

NASA's Solar System Exploration Program includes a program of "core missions" formulated by scientific advisory groups reporting to NASA and the competitive Discovery Program, in which missions are conceived and led by individual scientific investigators. The Venus Exploration of
The VEVA system consists of:

- Two balloon platforms floating at $60 \mathrm{~km}$ altitude

- Two atmospheric chemistry sondes deployed immediately after entry at Venus

- Eight small imaging sondes released to targeted sites during balloon traverses

Mission Overview: The VEVA mission involves the delivery of two identical payloads to Venus with a launch in 2004 and arrival and entry at 

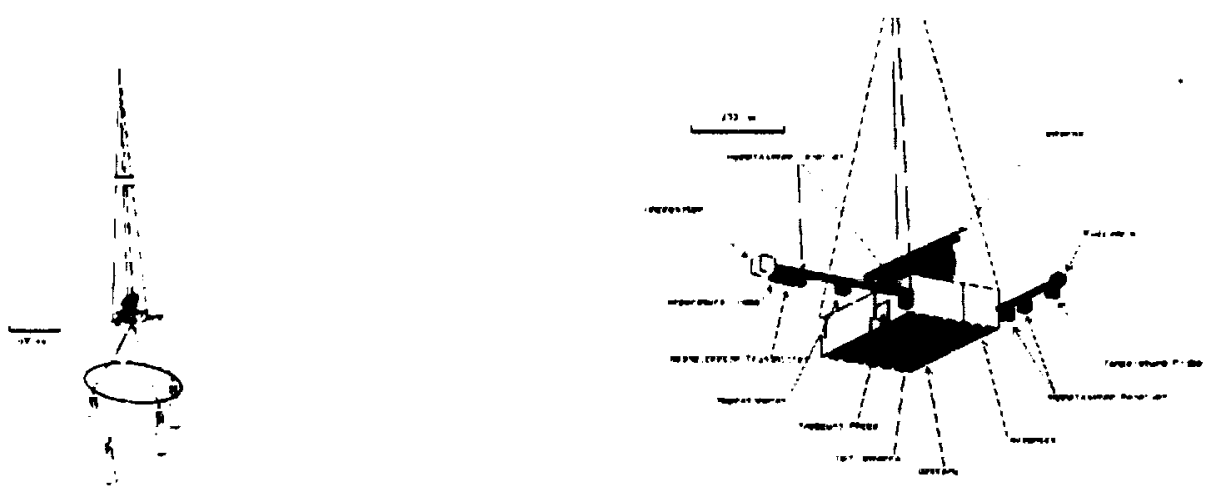

Fig 3: (a) The sonde support ring suspended from the VEVA gondola keeps the weight of sondes centered on the gondola after each sonde release (b) the gondola provide structure support for the science instruments and the communications antennae to enable collection and return of science data.

Venus about six months later (Fig 2). Each entry vehicle consists of a large sonde designed for atmospheric measurements and a balloon gondola system (Fig 3). An aerodynamic heat shield encloses the payload and provides initial g-load protection and support for the entry phase. After entry, the heat shield is jettisoned, the atmospheric sonde (Fig 4 (a) begins its fall to the surface and the balloon inflates arresting its descent and providing lift to maintain a $60-\mathrm{km}$ float height. The balloon carries an instrumented gondola with battery power for 7 days as it circles Venus (Fig 3). Each gondola carries four small (imaging) sondes (Fig 4 (b)) for release at different times during the mission. Several kinds of science measurement are made

- The two large sondes are released from their respective gondolas on entry and fall to the surface in about 37 minutes. They measure composition from below $20-\mathrm{km}$ altitude to the surface and an integrated suite of instruments provides a detailed characterization of the atmosphere.
- The eight smaller sondes free falls to $5 \mathrm{~km}$ above the surface where a small gliding parachute opens to slow the descent and provide horizontal offsets between successive images. These imaging sondes also carry an integrated atmospheric physics sensor suite to measure ambient conditions. Each sonde will be equipped at a minimum with an imaging system. Measurements of the chemistry in the low atmosphere is another key objective and microminiaturized mass spectrometers are being examined for this application

- The gondola also carries an atmospheric physics suite to measure ambient conditions at the $60 \mathrm{~km}$ altitude for a period of up to 7 days an will use a magnetometer to search for solar wind produced and intrinsic magnetic fields Radio tracking with the Deep Space Network will be used for precise measurements of horizontal winds

The primary communications mode for both

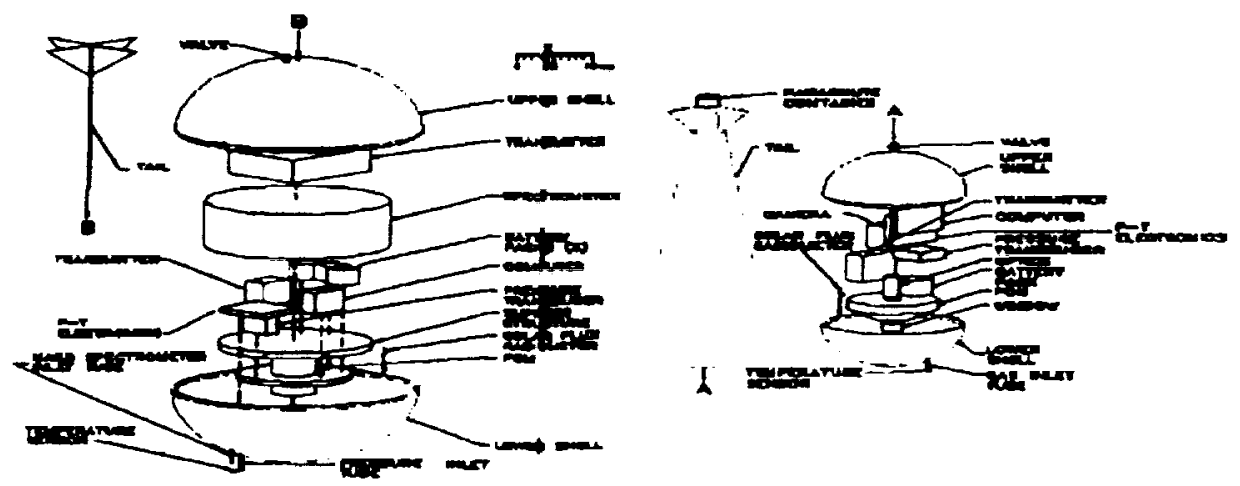

Fig 4: Miniaturization of instruments and supporting subsystems allow packaging in low mass vessels for thermal and pressure protection during the descent to Venus' surface.

4

American Institute of Aeronautics and Astronautics 


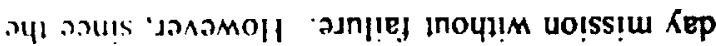

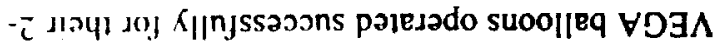

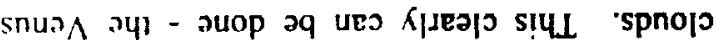

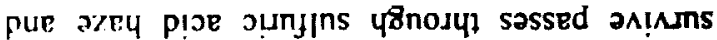

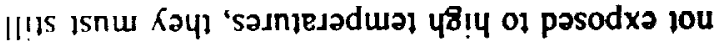

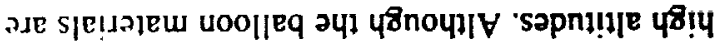

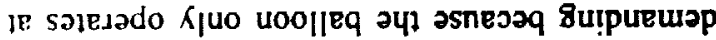

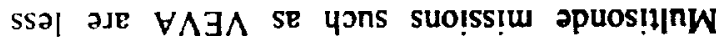

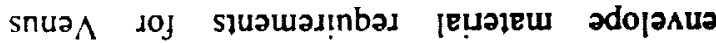

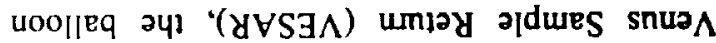

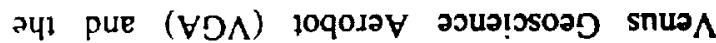
әчl ol pasedwo

(s) le is yगinoureyzrox אq Jəded

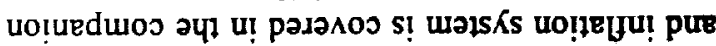

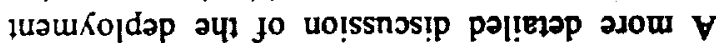

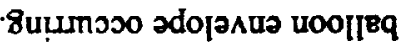

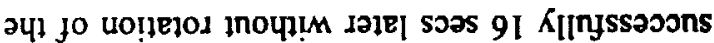

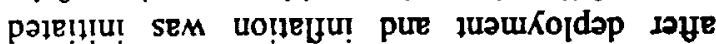

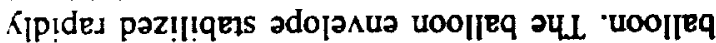

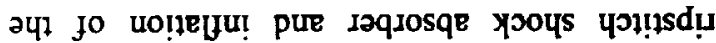

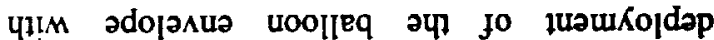

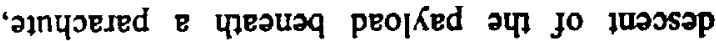

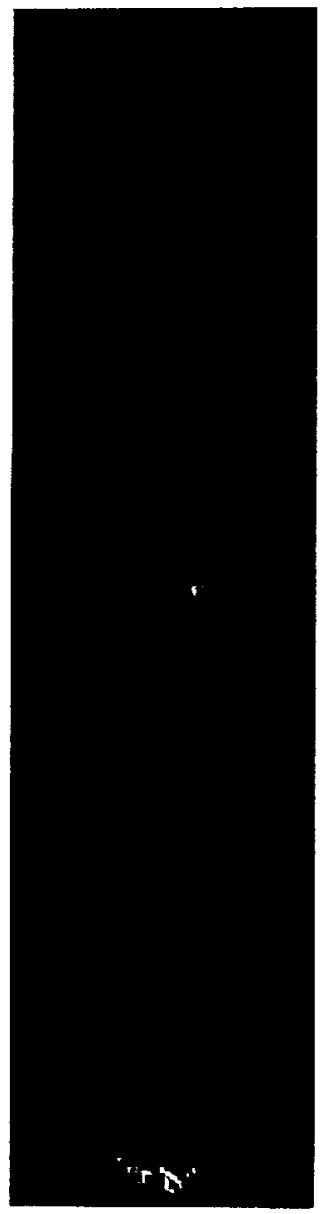

vaIA no pasn aq of qosoddde

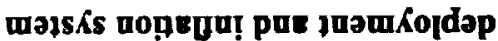

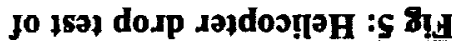
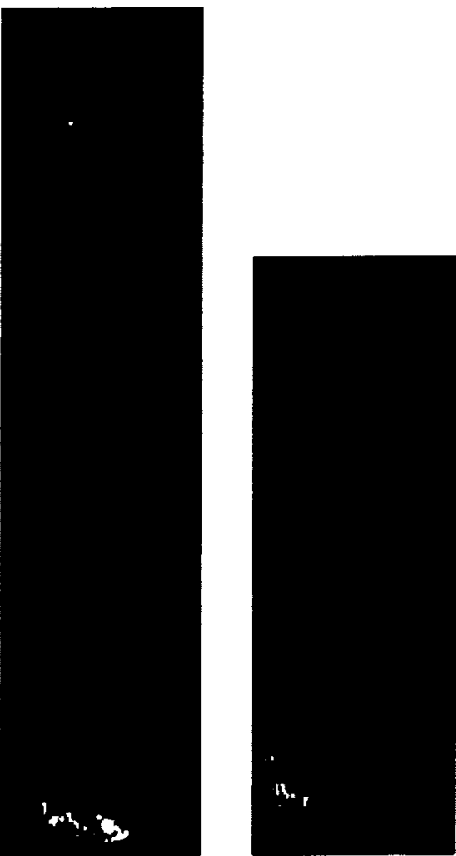

गY) SMOYS 5 8!

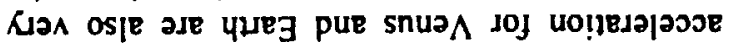

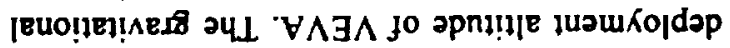

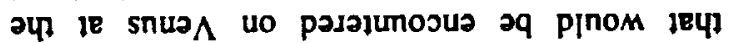

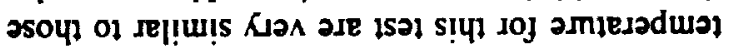
pure amssajd juəydsoule $24 \mathrm{~L}$ 'jesodosd

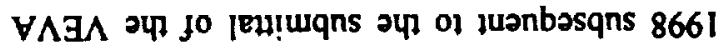

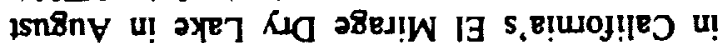

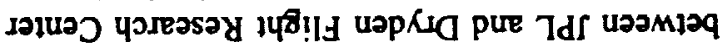
uoliededoos u! poisnpuos jsəi dorp soldos!

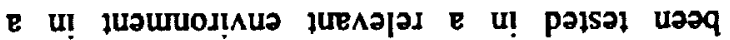

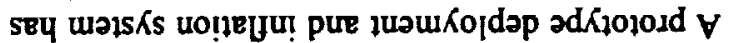

( ( गqE L) Uo!ss!

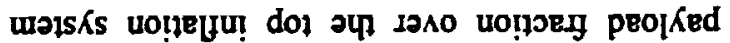

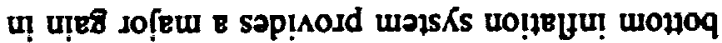

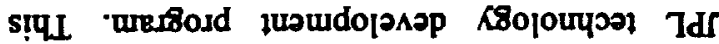

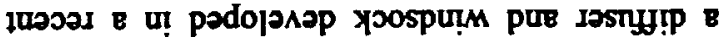

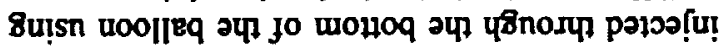

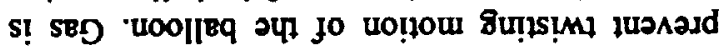

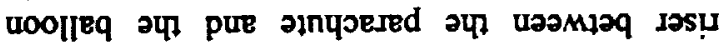

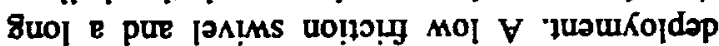

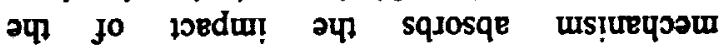

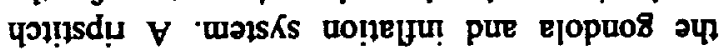

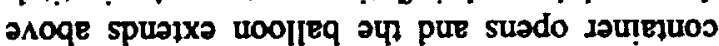

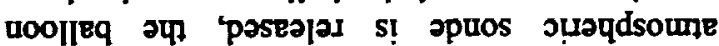

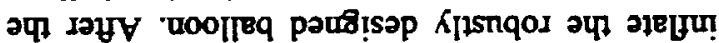

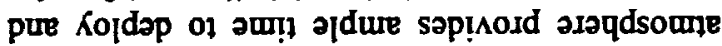

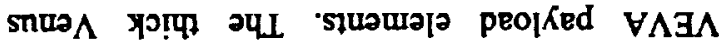

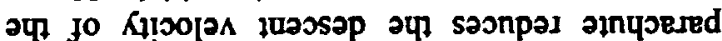

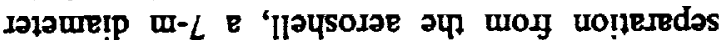
JoYV : uotwoluI puv mamiojda uoollog

- ว5uวrajuos s!̣ le sjaded uo!̣uedtuos

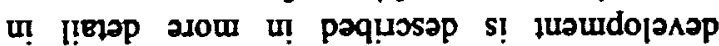

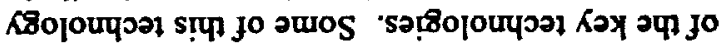

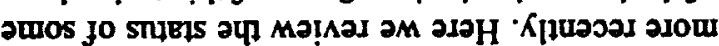

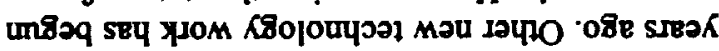

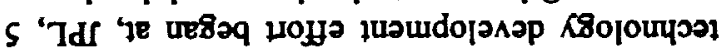

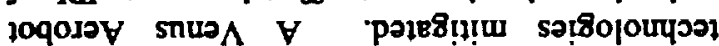

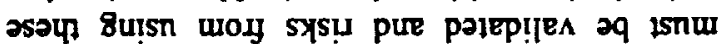

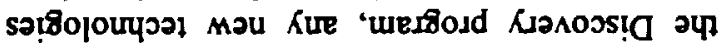

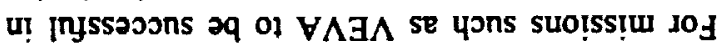

SNOISSIW JaNOSO\&OIW SANGA YOA LNAWdOTZAGA XDOTONHOZI

תeכא

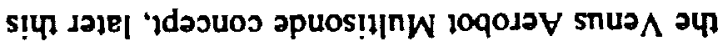
uo paseq osje "jesodosd mau e jo uo!ssiuqnsəs Jof Kemapun are sured tnq uoiss!uqns

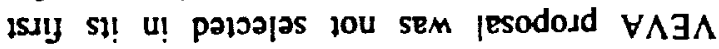
ว4.1. Uo!jewuju! [euo!!!sod 8u!nnseaw JO]

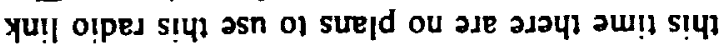

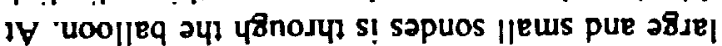


VEGA balloons were heavy and over-designed for that application, use of an improved material for VEVA has clear advantages.

Two concepts for such a balloon have been devised. Both seem feasible and the choice will be an engineering decision:

- The baseline proposed for VEVA is a bilaminated Mylar ( $23 \mathrm{um} \times 23 \mathrm{um}$ ) balloon with a Teflon sheath. This approach has heritage from the heavy Teflon cloth impregnated balloon flown on VEGA. It has been tested and shown to tolerate the sulfuric acid effects as described in the companion paper.

- An altemative balloon material is polyethylene/mylar laminate. Recent tests indicate that polyethylene is resistant to sulfuric acid. Relative to the Teflon sheath balloon, this approach has several advantages: it is a proven technology and a number of laminate balloons have been made: it is easier to pack and deploy: and an additional weight saving is possible since PE (density $0.95 \mathrm{gm} / \mathrm{cc}$ ) is much less dense than TFE (density $2.15 \mathrm{gm} / \mathrm{cc}$ ).

Technology work is continuing to further characterize these alternatives. Based on use of the bottom inflation technology and either of these approaches to balloon fabrication, the VEVA goals for payload fraction (Table 1) appear readily achievable.

Table 1: Comparison of VEVA and VEGA Payload Fraction

\begin{tabular}{|l|l|l|l|}
\hline PARAMETER & VEVA & VEGA & $\begin{array}{l}\text { BASIS FOR } \\
\text { ADVANCE }\end{array}$ \\
\hline $\begin{array}{l}\text { Mass of Balloon } \\
\text { System }\end{array}$ & $94 \mathrm{~kg}$ & $121 \mathrm{~kg}$ & \\
\hline Floating mass & $63 \mathrm{~kg}$ & $21 \mathrm{~kg}$ & \\
\hline $\begin{array}{l}\text { Payload to } \\
\text { Floating Mass } \\
\text { Fraction }\end{array}$ & 0.65 & 0.33 & $\begin{array}{l}\text { Lightweight } \\
\text { envelope } \\
\text { materials }\end{array}$ \\
\hline $\begin{array}{l}\text { Payload/Balloon } \\
\text { System Mass } \\
\text { Fraction }\end{array}$ & 0.44 & 0.06 & $\begin{array}{l}\text { Lightweight } \\
\text { bottom } \\
\text { inflation } \\
\text { system }\end{array}$ \\
\hline
\end{tabular}

Communications Technology: The VEVA mission uses the aerobot as a communications relay to temporarily store about 300 Mbits of data from each imaging sonde and then to relay
Table 2: Telecom Parameters for VEVA misoloa

\begin{tabular}{|l|l|l|}
\hline \multicolumn{1}{|c|}{$\begin{array}{c}\text { TELECOM } \\
\text { PARAMETERS }\end{array}$} & $\begin{array}{c}\text { DEEP } \\
\text { SPACE NET } \\
\text { TO } \\
\text { GONDOLA }\end{array}$ & $\begin{array}{l}\text { SONDE TO } \\
\text { GONDOLA }\end{array}$ \\
\hline $\begin{array}{l}\text { Maximum } \\
\text { Distance }\end{array}$ & $1.46 \times 10^{6} \mathrm{~km}$ & $200 \mathrm{~km}$ \\
\hline Upliak & & \\
\hline Power transmitter & $4 \mathrm{~kW}$ & $1 \mathrm{~W}$ \\
\hline Frequency & $7.17 \mathrm{GHz}$ & $400 \mathrm{MHz}$ \\
\hline Xmit antenna gain & $66.9 \mathrm{dBi}$ & $1 \mathrm{dBi}$ \\
\hline $\begin{array}{l}\text { Receive antenna } \\
\text { gain }\end{array}$ & $20 \mathrm{dBi}$ & $1 \mathrm{dBi}$ \\
\hline Data Rate & $125 \mathrm{BPS}$ & $500 \mathrm{KBPS}$ \\
\hline $\begin{array}{l}\text { Tumaround } \\
\text { Ranging }\end{array}$ & $\mathrm{Yes}$ & \\
\hline Xmit antenna gain & $24 \mathrm{dBi}$ & \\
\hline Downlink & & \\
\hline Power transmitter & $153 \mathrm{~W}$ & NA \\
\hline Frequency & $8.4 \mathrm{GHz}$ & NA \\
\hline & & NA \\
\hline $\begin{array}{l}\text { Receive antenna } \\
\text { gain }\end{array}$ & $68.1 \mathrm{dBi}$ & NA \\
\hline Data Rate & $10 \mathrm{KBPS}$ & NA \\
\hline
\end{tabular}

those data almost 150 million $\mathrm{km}$ from Earth. The parameters for the Earth-Gondola and the Sonde-Gondola communications links are shown in Table 2.

Sonde-Gondola Communications: The UHF system (Table 2) allows for transmission of data from two sondes simultaneously to their gondola at $500 \mathrm{kbps}$. Each gondola carries a preamplifier and two UHF receivers tuned to frequencies 10 to $15 \mathrm{MHz}$ apart plus Viterbi encoders. Sondes will be released so members of any pair that is within range of the gondola are transmitting on different frequencies. JPL is currently prototyping low power space-qualified transceivers meeting these requirements in the Microcommunications and Avionics System (MCAS) program. The sonde's transmit antenna and the gondola receiving antenna are mounted vertically to ensure their relative alignment and to minimize polarization loss.

Gondola-Earth Communications: This X-band system will be using standard deep space transponder technology developed for the solar system exploration program and used on planetary missions. The Small Transponding Modem (STM) currently under development is now expected to be ready for this missions and 
will provides range/doppler data on the gondola by phase coherent tumaround of the uplink signal sent from Earth.

The $X$ band antenna on the gondola is $20 \mathrm{~cm}$ in diameter and must maintain pointing at the Earth with an accuracy of about $5^{\circ}$. At insertion, the Earth is very close to the zenith, and no search would be needed for the initial acquisition. Servo control for the antennas pointing system is provided by using the AGC signal from the transponder's receiver as a measure of beacon signal strength. VEGA experience shows that we can expect long periods of stable flight with occasional periods of atmospheric downflow and turbulence. Control authority for telecommunications $\left(10^{\circ} / \mathrm{sec}\right)$ is expected to the volcanic plains of Rusalka Planitia. Eight sites have been identified along parallel traverses separated by $4^{\circ}$ of latitude $\left(0.7^{\circ} \mathrm{N}, 4.8^{\circ} \mathrm{N}\right)$.

Each balloon/gondola is deployed at $60 \mathrm{~km}$ altitude and drifts west at about $75 \mathrm{~m} / \mathrm{sec}$ with the Venus wind. They are launched just upwind of the prime targets and those for which targeting accuracy is most critical. These are the volcanoes Ozza Mons and Maat Mons. After drifting for about 2 hours, the balloon/gondolas are each over their first target and a timer is used to initiate the drop of the first imaging sonde. Studies of the Venus atmosphere indicate that, at $60 \mathrm{~km}$ altitude, the winds are quite predictable and that the mean wind speed is $0 \mathrm{~m} / \mathrm{s} N / S$ and $75 \mathrm{~m} / \mathrm{s} \mathrm{E} / \mathrm{W}$ and the wind uncertainty is $2 \mathrm{~m} / \mathrm{s} \mathrm{N} / \mathrm{S}$

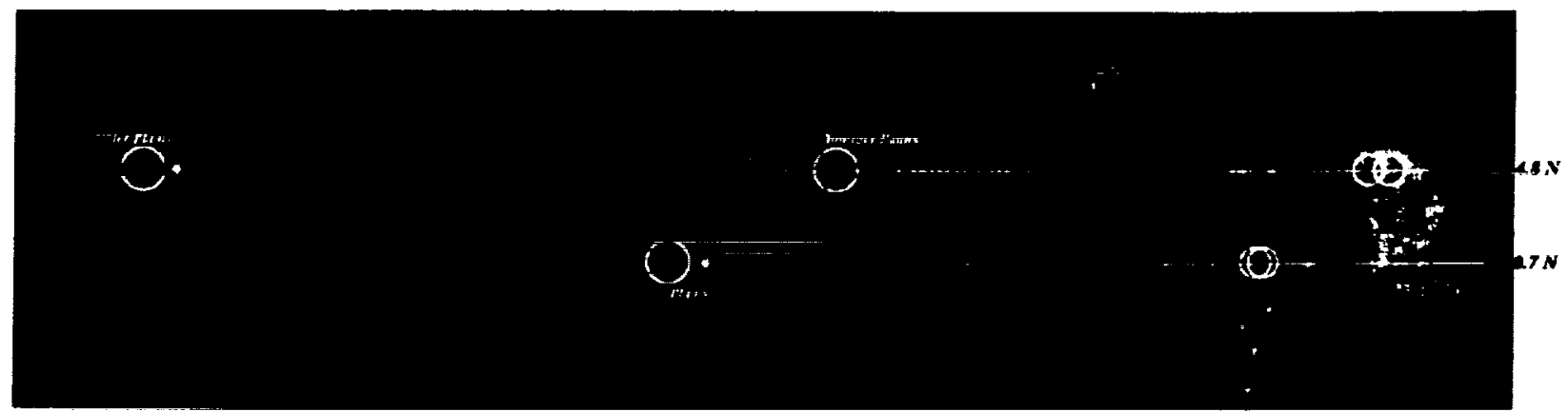

Fig 6: Magellan Radar image of the region on Venus $5.8 \mathrm{~S}$ to $11.8 \mathrm{~N}, 140$ to $206 \mathrm{E}$. The two baseline mission traverse paths are shown as white arrows extending from the East. The drop sonde targets are shown as circles corresponding to acceptable are for uncertainty in impact point.

suffice for residual gondola rotation $(1 \% \mathrm{sec})$ and small angle wobbles ( $5^{\circ}$ with oscillation periods of 30 to 60 secs to an accuracy of $2^{\circ}$. In the event of larger attitude disturbances, re-acquisition will be facilitated using an on-board attitude estimator. The possibility of using a sun sensor to achieve more rapid reacquisition of communications with Earth is also being explored as part of JPL's navigation and control research program.

Deployment of Imaging Sondes: The primary goal of the VEVA mission is to investigate evidence for global catastrophes that have dramatically modified the surface of Venus. The observational strategy that VEVA uses is to observe some key diagnostic landforms in a target area (Fig 6) that is almost twice the area of the United States and extending from the volcanic highlands of Atla Regio to the east to and $10 \mathrm{~m} / \mathrm{sec} \mathrm{E} / \mathrm{W}$. The balloon dispersion at the first target due to the winds is $+1-14 \mathrm{~km} \mathrm{~N} / \mathrm{S}$ and $=/-72 \mathrm{~km} \mathrm{E} / \mathrm{W}$. The total control dispersion includes the entry error.

The $E / W$ uncertainty can be reduced by using ranging and phase observations of the radio signal from the gondola and the altitude of the gondola giving a positional accuracy of about 10 $\mathrm{km}$. This technique was demonstrated on the VEGA mission. Balloon position is used to update the drop time to update the control error. This refinement is much more critical for targets further downwind and sonde control accuracy for these targets is expected to be 100 to $200 \mathrm{~km}$. The error is mainly in the N/S direction and therefore cannot be reduced further just by controlling the time of deployment. Continued work on path planning and prediction in NASA's Cross Enterprise Technology Development 
Program is directed at ways of improving targeting control and prediction and optimizing science data recovery from the imaging sondes. However, projected accuracy with current technology is acceptable for the success of the mission.

The balloons continue the westward drif, dropping imaging sondes at the other science targets. For the nominal arrival date at Venus of $9 / 26 / 2004$, sun elevation angle at the preselected sonde sites is at least $20^{\circ}$. All imaging data will be recovered before the balloon drift behind the limb of Venus and are out of communication contact with the Earth. The balloons continues to drift and take data on the far side of Venus emerging in view of Earth again at arrival +5 days. Science data acquired on the side of the planet away from Earth are downlinked and position fixes obtained. The mission ends at arrival +7 days.

Sonde Technology: Both the small and large sondes consist of spherical pressure vessels $\mathbf{3 2}$

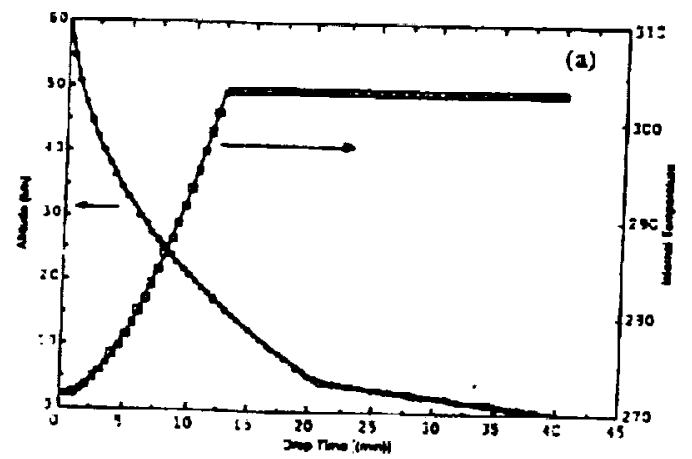

Fig. 7: VEVA Imaging Sonde Drop

$\mathrm{cm}$ and $18.4 \mathrm{~cm}$ in diameter respectively with stabilizing tail and fins for each sonde. The small sonde also features a streamlined aerodynamic fairing to decrease the drop time to the primary picture-taking altitude of $5 \mathrm{~km}$. The sonde's pressure vessel and thermal protection components allow survival to 92 bars and $460^{\circ} \mathrm{C}$ for the desired lifetime of each type of sonde. Instrument operating temperatures are maintained during descent using $15 \mathrm{~mm}$ thickness of xenon-gas filled porous fiberglass material as insulation inside the vessel walls, plus a heat sink comprised of lithium nitrate trihydrate phase-change material (also used by the Venera landers) which has a melting temperature of $30^{\circ} \mathrm{C}$. An optical window in each imaging sonde allows the camera a nadir view. The calculated descent profile and intemal temperature for the imaging (small) probe is shown in Fig 7. Note the constant internal temperature of $30^{\circ} \mathrm{C}$ due to melting of the phase

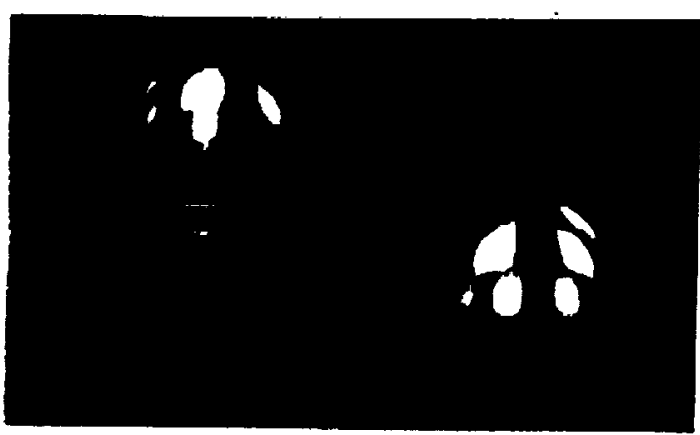

Fig 8: Prototype pressure vessel incorporating thermal insulation applicable to VEVA

change material, plus the "knee" in the descent profile due to the parachute deployment at $5 \mathrm{~km}$ altitude. The overall descent time for the large probe is about the same but it does not use a gliding parachute to brake its descent rate near the surface.

Thermal and mechanical technologies for compact vehicles for exploration of the deep Venus atmosphere have been under development at JPL for several years. Development of technology for short duration trips to the near surface of Venus was originally motivated by the needs of the Venus Geoscience Aerobot (VGA) mission that involved repeated descents to near the Venus surface. A concentric sphere design was selected for that mission with the $38 \mathrm{~cm}$ outer sphere taking the extemal pressure load, and the payload and phase-change material housed inside a $30-\mathrm{cm}$ diameter inner sphere. The concentric titanium sphere design originally was selected to permit vacuum multilayer insulation (MLI) between the two spheres. However, although vacuum MLI theoretically offers the best insulation performance, implementation difficulties associated with the need to maintain $10^{-5}$ tor vacuum in the presence of flanges, electrical feedthroughs and the hot, high pressure venusian environment subsequently prompted consideration of the more robust, reduced performance alternative of gas-filled fiberglass 
performance altemative of gas-filled fiberglass insulation. A prototype unit was built (Fig 7) and tested to evaluate the gas-filled fiberglass concept and the structural integrity of the lightweight vessel under pressure and high deceleration loading (7). This prototype did not include a window. Measured heat leaks on the prototype were $111 \mathrm{~W}$ for xenon gas and $256 \mathrm{~W}$ for nitrogen at a Venus strface temperature of $460{ }^{\circ} \mathrm{C}$. The xenon result is very close to the VGA performance target of $100 \mathrm{~W}$, suggesting that it is a viable altemative to the original vacuum MLI concept. The lightweight prototype was also successfully pressure tested to 92 bar, both at room temperature and Venus surface temperature. A final test was a 250-g centrifuge test, which was completely successful with posttest inspection revealing no damage or plastic deformation of gondola components. All of these demonstrated technologies are applicable to the VEVA drop sondes, although the internal sphere of the concentric design will not be needed in the absence of vacuum MLI.

On the basis of these tests, designs for both the large sonde and the small sonde were developed. A prototype thermal test model of the imaging (small) sonde is now being built which will incorporate improvements permitting more compact packaging. Experience with window technology from a JPL imaging probe which has been designed for photography of hot volcanic vents at the undersea Hawaiian volcano Lo'ihi is also being incorporated in the design of this system.

OTHER MULTISONDE MISSIONS: The Aerobot Sonde concept also has applications to Mars and Titan - the two other solar system bodies with atmospheres substantial enough for balloon flight. However, the motivations for using the sonde are somewhat different than at Venus and the sonde design will be driven by different factors.

Mars Aerobot with Microplane: At Mars, deployment can be used to perform close up observations of scientifically important but hazardous terrains such as strata exposed in the steep slopes of the deep canyons and rift systems of that planet. Rather than using a parachute to extend the duration of flight close to the surface of Mars, a glider, possibly with a rocket booster is an attractive approach (Ref 6). Such a concept, has been developed in collaboration with Georgia Institute of Technology and the Aurora Flight Sciences Company for a future Mars Micromission. The vehicle would not be designed to survive impact.

Titan Aerobot with Sonde: The Titan Explorer mission, now under definition by NASA, is likely to include an aerial platform, probably an aerobot, which would circumnavigate Titan. It would cross Titan's icy continents, which may be coated with organic materials precipitating from the atmosphere and traverse the ethane lakes or oceans that are believed to exist on this large satellite of Saturn. Titan's dense nitrogen atmosphere (almost five times as dense as that of Earth) and modest low-level winds should permit a Titan Aerobot to make safe, controlled descents to within several hundred meters of the Titan surface. Microsondes deployed from the aerobot would make it possible to characterize these potentially hazardous land surfaces before landing a larger and more expensive instrumentation for detailed investigations of the surface chemistry and the search for prebiotic chemicals.

CONCLUSION: The golden age of robotic balloon exploration of the planets is now beginning. The role of these aerobots will not be limited to carrying instrument payloads. Aerobots that are used as carriers for small, instrumented sondes that are capable of making measurements of short duration in hazardous areas is one such application. The aerobot can deliver the sondes precisely and serve a critical communications relay function. After collecting a burst of high rate data from the sondes, the data are stored on the aerobot and communicated across the vast reaches of interplanetary space over a period of hours to days. A Venus Multisonde mission is particularly attractive because of inability of obtain aerial imaging from orbit or high in the Venus atmosphere and the severe temperature environment near the Venus surface which makes long duration vehicles with present technology too costly. The Venus Exploration of Volcanoes and Atmosphere (VEVA) proposal to NASA's Discovery program submitted in June 1998 incorporated many of these ideas. A second proposal, embodying many of the same concepts, is planned in the near future. 


\section{Acknowledgements:}

The research described in this paper, was carriod out by the Jet Propulsion Laboratory, California Institute of Technology, under a contract with the National Aeronautics and Space Administration. Contributions from the other members of the VEVA team are gratefully acknowledged.

References:

(1) NASA's Roadmap for Solar System

Exploration, 1996. Published on the Internet at URL: http://eis.jpl.nasa.gov/roadmap/site/

(2) Venus Geoscience Aerobot, 1996, Published on the Internet at URL:

http://eis.jpl.nasa.gov/raadmap/site/nasa/earthen vironments/earth $12 . h t m$ l

(3) Venus Balloon Discovery Study by Venus Balloon Study Team, JPL Internal Report, September 23, 1997

(4) The VEVA Mission: Exploration of Venus Volcanoes and Atmosphere presented at the Lunar and Planetary Scientific Conference March 1999.
(5) Mars Aerobot Validation Program by V. Kerzhanovich et.al. AIAA Balloon Technology Conference 1999

(6) Evaluation of Materials for Venus Aerobot Applications by A. Yavrouian, G. Plett, S.P.S. Yen, J. Cutts and D. Baek AIAA Balloon Technology Conference 1999

(7) Technology Demonstration of a Gondola for Venus Deep Atmosphere Operations by Jeffery L.Hall, Paul D. MacNeal, Moktar A. Salama, Jack A. Jones and Matthew Kuperus Heun ALAA Journal of Spacecraft (in press) 